\begin{tabular}{|c|c|}
\hline 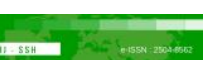 & Malaysian Journal of Social Sciences and Humanities (MJSSH) \\
\hline Malaysian Journal of & Volume 6, Issue 3, March 2021 \\
\hline (MJ-SSH) & e-ISSN : 2504-8562 \\
\hline & $\begin{array}{l}\text { Journal home page: } \\
\text { www.msocialsciences.com }\end{array}$ \\
\hline
\end{tabular}

\title{
Amalan Penggunaan Media Digital Guru-Guru di Sekolah Orang Asli
}

\author{
Aini Salwati Binti Mohd Yusof ${ }^{1}$ \\ Universiti Kebangsaan Malaysia (UKM) \\ Correspondence: Aini Salwati Mohd Yusof (p96019@siswa.ukm.edu.my)
}

\begin{abstract}
Abstrak
Penggunaan ICT (Information and Communication Technology) dalam pengajaran dan pembelajaran pada abad ke-21 ini memainkan peranan yang penting sejajar perkembangan semasa teknologi dunia. Walau bagaimanapun tahap pengetahuan murid-murid Orang Asli mengenai penggunaan teknologi ICT amat rendah. Justeru, peranan guru di sekolah Orang Asli menjadi pemangkin utama kepada perubahan ini. Kajian ini bertujuan melihat amalan penggunaan media digital guru-guru di sekolah Orang Asli. Reka bentuk kajian ini adalah kuantitatif melalui kaedah pengedaran borang soal selidik. Seramai 110 orang guru yang mengajar di sekolah Orang Asli dijadikan sebagai responden kajian. Tiga objektif utama dijadikan sebagai panduan kajian. Data kajian ini dianalisis menggunakan SPSS versi 24.0 secara deskriptif dalam bentuk peratusan dan min. Dapatan kajian ini menunjukkan pengetahuan guru terhadap media digital dan amalan penggunaan media digital dalam kalangan guru-guru Orang Asli berada pada tahap yang tinggi. Secara keseluruhannya amalan penggunaan media digital dalam kalangan guru-guru di sekolah Orang Asli adalah berada di tahap tinggi. Kajian ini turut mencadangkan penyelidikan di masa hadapan diperluaskan kepada minat murid-murid Orang Asli terhadap media digital yang merangkumi kajian perbandingan mengikut lokaliti serta tahap literasi murid-murid.
\end{abstract}

Kata kunci: tahap pengetahuan, media digital, amalan penggunaan, guru, kanak-kanak Orang Asli

\section{Practice of Using Digital Media Among Teachers in Indigenous School}

\begin{abstract}
The use of ICT (Information and Communication Technology) in teaching and learning in the $21^{\text {st }}$ century has played an important role in today's technological development. However, the level of knowledge of Indigenous students about the use of ICT technology is very low. As a result, the role of teachers in Orang Asli schools has been a catalyst for this change. This study aimed to look at the use of digital media by teachers in Orang Asli schools. The design of this study was quantitative through the method of distributing questionnaire forms. A total of 110 teachers who were teaching at Orang Asli schools were identified as respondents of the study. The three main objectives serve as the study guide. The data of this study was analyzed using SPSS version 24.0 in descriptive form of percentage and mean. The findings of this study show that teachers' knowledge of digital media and the use of digital media among Indigenous teachers are at a high level. Overall the use of digital media among teachers in Orang Asli schools is high. The study also proposes that future research be extended to indigenous
\end{abstract}


students' interest in digital media, which includes comparative study of localities and student literacy levels.

Keywords: level of knowledge, digital media, practices, teachers, Indigenous

\section{Pengenalan}

Penggunaan ICT (Information and Communication Technology) dalam pengajaran dan pembelajaran pada abad ke-21 ini memainkan peranan yang penting sejajar perkembangan semasa teknologi dunia. Perkembangan ini mencetuskan anjakan ke- 8 dalam Kementerian Pendidikan Tinggi Malaysia (KPTM) dengan menjalankan sistem pembelajaran dalam talian secara global (Pelan Pembangunan Pendidikan Tinggi Malaysia 2013-2025) sebagai satu langkah kehadapan bagi mengimbangi kepesatan Pendidikan negara-negara maju. Anjakan ke-7 KPM dan juga Lonjakan ke-8 KPTM ini jelas menunjukkan bahawa dunia pendidikan pada masa kini sangat bergantung kepada ICT yang sangat penting dalam membantu proses PdP seterusnya menjadikannya lebih menarik dan berkesan (Khadijah et al., 2014; Hasnuddin et al., 2015; Rogayah \& Mohd Aderi, 2016).

Perkembangan ICT ini telah mendatang satu perubahan besar dalam bidang Pendidikan khususnya melibatkan aspek pengajaran dan pembelajaran di sekolah dan peringkat pengajian tinggi (Rogayah \& Mohd Aderi, 2016). Dalam hal ini, Christina dan Hazman (2009) menjelaskan, situasi ini menuntut institusi-institusi pendidikan melakukan perubahan yang menjurus kepada penyediaan dan pembangunan modal insan. Kerangka ini perlu dilaksanakan secara terperinci bagi mencapai status negara maju dalam bidang pendidikan pada masa terdekat (Marlina et al., 2016). Keperluan terhadap ICT ini telah menjadi satu keperluan utama yang perlu dimanfaatkan oleh semua lapisan masyarakat bagi melahirkan generasi yang berfikiran global dan tidak ketinggalan dalam aspek ini (Syuhada \& Mohd Aderi, 2016; Khairun Nisak et al., 2016).

Pendidikan global adalah usaha untuk memupuk perspektif tentang dunia kepada individu dengan menekankan hubungan antara budaya dan kemanusiaan. Secara umumnya, kewujudan teknologi tanpa sempadan memudahkan urusan manusia yang mencakupi pelbagai aspek kehidupan. Arus pemodenan dan kecanggihan dalam bidang teknologi digital seharusnya dirasai oleh golongan Orang Asli kerana slogan "Pendidikan Adalah Untuk Semua" yang diwar-warkan oleh Kementerian Pendidikan Malaysia haruslah disahut oleh warga pendidik supaya tiada keciciran golongan murid Orang Asli dalam arus pendidikan.

Perkembangan teknologi yang pesat bak cendawan tumbuh lepas hujan telah merubah fenomena yang luar biasa. Perubahan ini sedikit sebanyak telah mempengaruhi corak pemikiran manusia. Pada masa kini, penggunaan teknologi dalam kehidupan seharian sudah menjadi darah daging bagi setiap individu tidak kira peringkat umur di bandar dan di luar bandar. Kecanggihan peranti, gajet dan kesinambungan internet telah menerobos sempadan pemikiran manusia sehingga ianya menjadi makanan seharian setiap individu. Peranti berteknologi canggih serta akses internet pada masa kini boleh didapati dengan pantas dan mudah di mana jua kita berada. Inovasi dalam pelbagai sumber teknologi ini dihasilkan sehingga membolehkan komunikasi dan interaksi manusia masa kini lebih pantas serta berupaya melampaui batasan masa dan tempat (Portal Rasmi Arkib Negara Malaysia, 2015).

\section{Sorotan Literatur}

Kajian ini memfokuskan kepada amalan penggunaan media digital dalam kalangan guru-guru di sekolah Orang Asli. Dalam sistem pendidikan, penggunaan alatan berteknologi merupakan medium yang tidak asing lagi bagi menyalurkan informasi dalam pendidikan khususnya dan medan komunikasi amnya. Seperti yang sedia diketahui, media merupakan perantara dalam menyebarkan maklumat dalam pelbagai senario sama ada visual, grafik, audio mahupun buku berelektronik. Medium perantaraan seperti ini 
bukan sahaja digunakan untuk menyebarkan maklumat, malah sebagai saluran tentang perkembangan info dalam dunia pendidikan.

Penggunaan media digital dalam PdPc merupakan satu tarikan kepada tumpuan murid-murid tentang subjek yang diajar berbanding pengajaran secara tradisional sahaja. Kajian Mohd Noorhadi dan Zurinah (2017) menyatakan pelaksanaan PdPc memerlukan guru memiliki kreativiti dan inovasi supaya minat belajar di kalangan murid-murid dapat terbina. Justeru itu, penggunaan media digital yang berpaksikan teknologi boleh menjadi pemangkin kepada pembelajaran lestari. Kajian-kajian lepas banyak memberi fokus kepada pemahaman terhadap konsep media digital, sikap dan kesediaan para pendidik untuk mengintegrasikan bahan berteknologi dalam pengajaran (Miarso, 2004; Yusup \& Razmah, 2006; Faridanura, 2014; Fadzliaton, 2015; Arulnathan, 2015;).

Orang Asli merupakan masyarakat pribumi yang paling awal yang mendiami Tanah Melayu sejak abad ke-8 SM. Fauzi (2006) menjelaskan, hasil penemuan menerusi penyelidikan arkeologi di beberapa penempatan awal di kawasan pergunungan timur dan utara semenanjung Malaysia menunjukkan, penempatan awal Orang Asli telah bertapak sejak 10,000 tahun yang lalu. Abdul Razak Ahmad dan Zalizan Mohd Jelas (2009) menjelaskan bahawa takrifan Orang Asli merujuk kepada 'tulen' atau 'masyarakat pertama' yang mendiami Semenanjung Malaysia. Unjuran yang dikeluarkan oleh JAKOA pada tahun 2010 menunjukkan bilangan Orang Asli di Malaysia adalah seramai 178,197 dengan nisbah 0.5 peratus daripada populasi penduduk Malaysia (JAKOA, 2012).

Dalam perlembagaan Malaysia, perkara 17 Akta Orang Asli 1954 (Akta 134) semakan 1974 menjelaskan bahawa Orang Asli merupakan anak kepada seorang bapa dari kalangan masyarakat Orang Asli. Kedudukan mereka sebagai Orang Asli adalah tertakluk kepada amalan, adat dan budaya serta kepercayaan dalam masyarakat mereka. Kelompok Orang Asli dibahagikan kepada tiga pecahan utama iaitu Senoi yang merupakan kelompok terbesar masyarakat di Malaysia, diikuti oleh Melayu Proto dan Negrito (Nicholas, 2000).

Daripada tiga kelompok besar Orang Asli di Malaysia, terdapat 18 pecahan suku kaum yang bertebaran di seluruh semenanjung Malaysia. Setiap suku kaum tersebut mempunyai perbezaan berdasarkan asal usul, tutur bahasa dan bentuk rupa paras dan fizikal (JHEOA, 2010). Bagi kelompok Senoi, terdapat enam suku kaum iaitu Semai, Temiar, Jah Hut, Che' Wong, Mah Meri dan Semaq Beri yang menghuni kawasan di sekitar Negeri Perak dan Pahang. Kelompok Melayu-Porto pula terbahagi kepada enam suku kaum iaitu Temuan, Semelai, Jakun, Kanaq, Orang Kuala dan Orang Seletar yang menetap di beberapa kawasan Pahang, Johor, Negeri Sembilan dan Selangor. Bagi kelompok ketiga iaitu Negrito juga terdapat enam pecahan suku kaum iaitu Kensiu, Kintak, Jahai, Lanoh, Mendriq dan Bateq yang berpusat di kawasan pendalaman Kelantan, Perak dan Pahang (Khor \& Mohd Shariff, 2008). Perincian tersebut boleh digambarkan menerusi rajah berikut:

\section{Pendidikan dan Orang Asli}

Perkembangan pendidikan Orang Asli telah bermula sejak 1930an yang bertujuan untuk menjadikan mereka tahu membaca dan menulis hasil usaha mubaligh Kristian (Hasan Mat, 1998). Tambahan beliau lagi, walaupun usaha pihak mubaligh Kristian ini dilihat sebagai batu loncatan kepada perubahan dan perkembangan pendidikan Orang Asli, terdapat agenda yang diterapkan oleh mereka untuk menyebarkan agama dan kefahaman menerusi pendidikan. Hasil daripada kebolehan Orang Asli membaca dan menulis, agama mereka akan mudah berkembang seiring dengan usaha dakwah mereka.

Perkembangan pendidikan formal bagi Orang Asli bermula pada tahun 1953 selepas kerajaan menubuhkan Jabatan Hal Ehwal Orang Asli (JHEOA) yang bertujuan menjaga kebajikan Orang Asli termasuk pendidikan mereka. Zainal (2008) menjelaskan, penubuhan JHEOA adalah usaha kerajaan bagi membantu dan memberi perhatian kepada masyarakat minoriti ini agar tidak terus terpinggir oleh arus pemodenan semasa negara. Oleh itu, dengan termaktubnya Akta 134 dalam perlembagaan Malaysia, hak Orang Asli akan terus dibela dan JHEOA akan terus melaksanakan tugas mereka bagi menjaga kepentingan Orang Asli (Hassan Ishak, 1998). Bagi memastikan pendidikan Orang Asli terus 
berkembang, JHEOA telah ditukar dengan nama Jabatan Kemajuan Orang Asli (JAKOA) yang berterusan menjalankan perancangan pelan pembangunan Orang Asli secara jangka pendek dan jangka panjang (Zainal, 2019). Dalam masa yang sama, pemantauan berterusan dilaksanakan bagi memastikan keberkesanan pembelajaran yang diterapkan sesuai dengan keadaan dan kondisi anak-anak Orang Asli (Zainal, 2004).

Kehidupan anak-anak Orang Asli sememangnya dahagakan ilmu pengetahuan apatah lagi mereka hidup jauh di pedalaman di mana mereka kurang mendapat tempias ledakan perkembangan teknologi. Namun begitu, murid-murid Orang Asli kebanyakannya sudah mengikuti arus pemodenan dalam industri pendidikan malah ada yang sudah berjaya mendapat pencapaian yang cemerlang dalam pendidikan mereka. Dapatan Jabatan Kemajuan Orang Asli (JAKOA), seperti yang dinyatakan oleh Azwa (2018), Jay Nurivanna Asrienza Jaya berketurunan Orang Asli Suku Temuan merupakan seorang graduan Sarjana Muda Sains Komputer dari Fakulti Sains Komputer dan Teknologi Maklumat dan juga pelajar tajaan biasiswa dari Jabatan Kemajuan Orang Asli (JAKOA) telah mendapat keputusan yang membanggakan. Kini beliau bekerja di salah sebuah firma di Kuala Lumpur. Maka bersesuaian dengan hasrat kerajaan iaitu melihat kemajuan dan pencapaian cemerlang anak Orang Asli dalam pelbagai bidang termasuk sukan pendidikan.

Misi untuk meningkatkan taraf hidup golongan komuniti Orang Asli memang merupakan perkara utama yang menjadi agenda kerajaan bagi merealisasikan pembangunan yang inklusif dan setara (Wan Afizi at el., 2014). Sejajar dengan itu, Kementerian Pendidikan memastikan tidak ada golongan yang tersisih daripada sistem pendidikan dengan menyediakan ruang seluasnya kepada etnik itu mendapat pendidikan setanding masyarakat lain. Selain itu, guru-guru yang terlatih turut dihantar untuk mengajar di sekolah anak-anak Orang Asli di samping pembinaan dan penyediaan bangunan sekolah yang selesa dan sesuai. Kelengkapan dan keperluan Pdpc juga ditambahbaikkan bagi membolehkan anak-anak Orang Asli tidak ketinggalan khususnya melibatkan penggunaan teknologi dan media digital (Maszlee, 2019).

\section{Media digital dan amalan guru dalam PdPc}

Penggunaan ICT atau media digital dalam PdPc secara jelas akan membantu para guru mengubah gaya persembangan dalam pengajaran melalui kaedah yang lebih efektif. Pendekatan ini secara langsung akan menarik minat murid untuk memberi lebih tumpuan kepada penyampaian guru dalam kelas. Penggunaan media digital ini tidak terbatas kepada internet semata-mata, bahkan meliputi penggunaan sumber multimedia seperti televisyen, video, aplikasi dalam talian dan lain-lain yang akan memberi kesan yang berbeza kepada suasana pembelajaran. Selain itu, penglibatan pelajar dalam proses pembelajaran menerusi media digital ini dapat memberi peluang kepada mereka untuk meneliti dan mengambil peluang berhubung dengan rakan dan pakar dari seluruh dunia (Izzah, 2011).

Di Amerika contohnya, etnik minoriti di sana dilihat kurang menggunakan komputer bagi mencari maklumat berkaitan pengajian sebagai persediaan untuk ke kelas (Volman, 2005). Dalam hal ini, apabila komputer jarang digunakan, maka internet juga tidak mampu untuk mereka gunakan secara maksimum, walaupun alat media digital ini telah disediakan di sekolah mereka. Eccles (1994) menyatakan bahawa, para guru dan ibu bapa dapat memberi pengaruh yang positif kepada golongan muda untuk menggunakan komputer dan internet sebagaimana yang dinyatakan dalam 'value-expectancy theory'. Pandangan ini adalah perlu diaplikasikan bagi membentuk potensi murid-murid secara global melalui kemahiran yang diperoleh daripada pendidikan yang diterima mampu diaplikasikan atau diadaptasi oleh murid-murid dalam kehidupan seharian.

Penggunaan sumber pendidikan seperti media digital secara terancang dan teratur akan menjadikan proses PdPc lebih bermakna dan berkesan selain membantu guru menerangkan sesuatu konsep pengajaran dengan lebih mudah dan menarik serta membantu murid memahami perkara yang dipelajari dan mencapai objektif.

Pendidikan yang mengimplementasikan digital dalam pengajaran merupakan satu bidang dan amalan etika yang dipraktikkan untuk memudah cara dan meningkatkan keberkesanan PdPc (Sumber 
Pendidikan, 2015). Sejajar dengan Garis Panduan Pembelajaran Abad ke-21 dan diantara ciri-ciri pembelajaran PAK21 juga semuanya terkandung dalam Pelan Pembangunan Pendidikan Malaysia 20132025 yang telah dilancarkan sebelum ini yang boleh dimanfaatkan ialah pembelajaran berpusatkan pelajar, aplikasi ICT, pembelajaran aktif, pembelajaran kendiri, persekitaran yang kondusif, saling hormat menghormati, bertanggungjawab, penilaian berasaskan pencapaian dan pembelajaran kolaboratif. Sehubungan dengan itu, guru-guru boleh mempelbagaikan kreativiti pengajaran sebagai alternatif untuk menyampaikan maklumat.

Menurut Briggs (1977), media adalah alat untuk memberikan perangsang bagi siswa supaya terjadi proses belajar. Association of Education Communication Technology (AECT), media adalah segala bentuk dan saluran yang dipergunakan untuk proses penyaluran pesan. Menurut Gagne pula media adalah berbagai jenis komponen dalam lingkungan siswa yang dapat merangsang siswa untuk belajar. Menurut Miarso (2004), media adalah segala sesuatu yang dapat digunakan untuk menyalurkan pesan yang dapat merangsang fikiran, perasaan, perhatian dan kemahuan siswa untuk belajar. Heinich, dan Russel (1993) teknologi atau media pembelajaran sebagai penerapan ilmiah tentang proses belajar pada manusia dalam tugas praktikal belajar mengajar.

Integrasi media dan digital membentuk satu maksud kesepaduan media pembelajaran sama ada formal atau tidak formal yang menggabungkan media digital dalam talian secara beretika, professional dan secara klinikal dengan kaedah tradisional. Walau bagaimanapun, peningkatan media digital tidak bererti media tradisional tidak lagi relevan di Malaysia. Nielsen Consumer and Media View menunjukkan bahawa pada tahun 2017, data menunjukkan bahawa lebih daripada 90\% rakyat Malaysia muda berusia antara 15 hingga 24 tahun menggunakan media tradisional dan digital; hanya $1 \%$ daripada demografi ini yang menggunakan media digital semata-mata dalam tempoh masa (Yusup Hashim dan Razmah Man, 2006)

\section{Facebook}

Facebook mulai dicipta pada tanggal 4 Februari 2004 oleh Mark Zuckerberg bersama rakan-rakan sekuliahnya di University of Harvard, di antaranya Eduardo Saverin, Andrew McCollum, Dustin Moskovitz dan Chris Hughes (Mohd. Noorhadi, 2017). Kajian Arulnathan (2015), aplikasi facebook digunakan bagi membantu pelajar-pelajar belajar secara bersemuka dan secara tidak langsung mereka terlibat dalam perbincangan secara atas talian. Pendekatan laman sosial dapat melatih pelajar berkomunikasi secara aktif disamping membina pengetahuan menerusi penggunaan internet (Faridanura, 2014).

Memandangkan Facebook telah menjadi salah satu perhubungan yang sangat terkenal dewasa kini, maka guru-guru seharusnya mengambil peluang ini untuk menggarap aplikasi Facebook sebagai satu wacana penyebaran ilmu dan mendapatkan maklumat dalam PdPc. Para guru dapat mendapat maklumat dengan pantas dan afektif. Namun begitu, etika penggunaan internet dan melayari Facebook haruslah diselia dengan baik supaya rangkaian sosial ini tidak disalahgunakan.

Di Malaysia, penggunaan Facebook telah menjadi satu keperluan kepada semua tanpa mengira lapisan masyarakat. Selain daripada medium untuk berhubung dan berkomunikasi, facebook juga merupakan antara teknologi yang diguna pakai untuk tujuan Pendidikan. Hal ini merujuk kepada fungsi Facebook yang tidak sekadar tempat luahan dan penceritaan semata-mata, bahkan terdapat padanya perkongsian ilmu yang bermanfaat khususnya dalam bidang Pendidikan. Rangkaian sosial ini bukan hanya sebagai "perpustakaan maklumat" yang berfungsi sebagai agen penyebaran maklumat kepada khalayak ramai, bahkan fungsi dan peranannya lebih daripada itu. Tambahan pula, dengan kewujudan teknologi web 2.0 pada hari ini, penggunaan Facebook telah mencapai satu tahap yang luar biasa dengan banyak perkara boleh dilakukan dengan hanya satu rangkaian sosial ini (Siti Ezaleila et al., 2010).

Faridanura (2014) menyatakan bahawa, Facebook boleh menjadi wadah perbincangan ilmiah antara pelajar dengan guru selain daripada perkongsian maklumat berkaitan pembelajaran. Zulaikha dan Ridzuan (2019) menjelaskan bahawa penggunaan Facebook dapat meningkatkan tarikan kepada murid 
berdasarkan penerapan elemen teknologi terkini dalam Facebook melalui aktiviti pembelajaran yang mampu meningkatkan kepelbagaian kaedah pengajaran dan pemahaman murid. Justeru, dengan penggunaan Facebook ini, peranan guru tidak sekadar berada dalam bilik darjah sahaja, bahkan meliputi atas talian yang boleh diakses oleh murid-murid walaupun di luar dari tempoh pembelajaran.

\section{Google Classroom atau Bilik Darjah Google}

Bilik Darjah Google atau dikenali sebagai "Google Classroom" merupakan perkhidmatan web secara percuma, yang dibangunkan oleh Google untuk sekolah bermula tahun 2014. Penggunaan 'Google apps' adalah sangat berkesan kerana pelajar boleh menghantar tugasan secara maya pada bila-bila masa dan tempat. Disamping penjimatan kos pencetakan dan masa. 'Google apps' didapati mempunyai ciri-ciri keselamatan yang tinggi kerana pengguna tidak perlu bimbang tentang pencerobohan data.

Ani Omar (2019) menjelaskan bahawa penggunaan aplikasi Google dalam pengajaran dan pemudahcaraan akan memupuk pemikiran kreatif dan inovatif dalam kalangan pelajar. Kaedah berasaskan teknologi ini berupaya menghilangkan rasa bosan pelajar terhadap pembelajaran terutamanya melibatkan teori dan fakta yang kurang menarik. Oleh demikian, penggunaan aplikasi Google Plus dan Google Classroom akan memantapkan kaedah PdPc yang lebih berkesan dan interaktif seperti penyediaan kuiz dan gerak kerja atas talian yang lebih menarik.

Selain itu, pengajaran dan pembelajaran menggunakan perisian Google ini tidak hanya tertumpu kepada aplikasi Google Plus dan Google Classroom, bahkan melibatkan perisian seperti Google Form, Google Doc, Google Maps, Google Translate dan Google Sketch Up (Suzana \& Fariza, 2014). Kesemua perisian ini memiliki keupayaan yang lebih luas dalam pengurusan pembelajaran yang akan meningkatkan motivasi guru dan pelajar. Perkembangan ini telah membuka ruang maya yang cukup luas kepada pelajar dalam mencari ilmu. Penyimpanan sumber rujukan dalam kapasiti yang besar telah diselesaikan dengan aplikasi Google Drive yang memberi kemudahan kepada guru dan pelajar untuk menyimpan dan mengakses maklumat yang bersaiz besar.

Walau bagaimanapun, terdapat juga kekurangan utama dalam penggunaan sistem ini iaitu rangkaian internet yang laju. Jika dilihat kepada trend peningkatan keupayaan melayari internet pada hari, rata-rata kawasan bandar telah memperoleh keupayaan yang luas untuk melayari internet. Namun, bagi kawasan luar bandar atau pendalaman, kesukaran memperoleh internet akan merencatkan keupayaan penggunaan aplikasi Google ini.

\section{Youtube}

Youtube merupakan salah satu rangkaian sosial yang semakin popular di kalangan netizen melalui portal dan aplikasi dalam telefon pintar. Selain dari sumber penyebaran maklumat melalui video dan audio, pengurusan youtube telah meningkatkan kebolehcapaian yang mampu untuk menjana pendapatan yang sangat lumayan oleh youtuber. Melalui peningkatan kemudahan yang disediakan, maklumat yang terdapat dalam youtube tidak sekadar merujuk kepada hiburan semata-mata, bahkan telah meluas sehingga perkongsian ilmu dan pengajaran dibuat melaluinya. Tenaga pengajar sambilan telah menjadikan youtube sebagai medium penyampaian utama mereka melalui video dan audio yang dilihat lebih inovatif dan kreatif. Siti Rokiah dan Fadzli (2015) menjelaskan, generasi Y mudah terpengaruh dengan penggunaan youtube khususnya dalam bidang hiburan. Dalam hal ini, kreativiti dari guru-guru amat diperluaskan untuk menarik pelajar-pelajar melayari video-video pengajaran yang menarik dan bermanfaat.

Lewin (2010) menjelaskan bahawa pihak youtube telah merekodkan sebanyak 65,000 video dimuat naik setiap hari dan 100 juta tontonan di youtube pada tahun 2006 dan mencecah 2 bilion setiap hari pada tahun 2010. Angka ini menggambarkan bahawa kecenderungan masyarakat khususnya pelajar-pelajar untuk melayari video-video dalam youtube ini sangat tinggi. Justeru itu, para guru perlu memanfaatkan penggunaan youtube ini dalam PdPc bagi meningkatkan minat pelajar untuk memahami sesuatu ilmu. 
Penggunaan grafik dan warna secara langsung dapat menarik minat dan perhatian pelajar seterusnya menghindarkan salah anggapan dan tafsiran (Che Suriani \& Fariza, 2014). Dalam konteks pembelajaran seperti bahasa Inggeris, bahasa Arab dan sebagainya, penggunaan medium youtube ini sangat diperlukan bagi memperoleh gambaran sebenar tentang sebutan dan penggunaan istilah dari penutur jati sesuatu bahasa tersebut (Rahil et al., 2016). Dengan kaedah ini, pelajar akan cepat memahami dan menuruti setiap olahan yang dikemukakan berbanding mendengar daripada sisi guru yang mengajar. Oleh yang demikian, para guru dapat mengenal potensi pelajar mereka dengan lebih cepat dan tepat.

\section{Teori Tingkah Laku Berencana}

Teori tingkah laku berencana atau juga dikenali dengan Theory of Planned Behaviour (TPB) telah digunakan secara meluas dalam pelbagai bidang penyelidikan untuk meramal tingkah laku dengan berjaya (Armitage \& Conner, 2001). Dalam persekitaran organisasi, teori tingkah laku berencana telah digunakan untuk memahami keseimbangan kerja dan hidup (McCarthy, Darcy \& Grady, 2010), niat untuk pemindahan latihan (Al-Eisa et al., 2009), niat untuk melantik orang kurang upaya (Ang, Ramayah \& Amin, 2015), niat untuk menyertai organisasi (Warmerdam, Lewis \& Banks, 2015), penggunaan teknologi (Baker, Al-Gahtani \& Hubona, 2007), niat pekerja terhadap program penglibatan pekerja (Dawkins \& Frass, 2005), dan niat untuk terlibat dengan salah laku akademik (Stone, Jawahar \& Kisamore, 2009).

Dalam konteks perubahan organisasi pula, beberapa kajian telah menggunakan teori tersebut antaranya niat tingkah laku menyokong perubahan (Jimmieson et al., 2008) dan tingkah laku menyokong perubahan (Kim et al., 2011). Kejayaan teori tingkah laku terancang untuk meramal tingkah laku dengan berjaya dalam pelbagai bidang penyelidikan khususnya perubahan organisasi berencana mendorong penyelidik untuk menggunakannya bagi meramal tingkah laku murid-murid Orang Asli apabila didedahkan dengan amalan penggunaan media digital dalam pengajaran di sekolah.

Berdasarkan teori tingkah laku berencana (Ajzen, 1991), dapat difahami bahawa individu membuat keputusan secara sedar untuk melibatkan diri dalam tingkah laku tertentu, dan ianya dipengaruhi oleh (a) sikap iaitu kepercayaan peribadi terhadap tingkah laku dan penilaian terhadap hasilnya, (b) norma subjektif iaitu kepercayaan normatif mengenai kebolehinginan sosial dan jangkaan tekanan sosial untuk melaksanakannya, dan (c) jangkaan kawalan tingkah laku iaitu kepercayaan kawalan mengenai keupayaan dan peluang untuk melakukan tingkah laku masing-masing (Ajzen, 1991). Berdasarkan pemahaman ini, jangkaan kawalan tingkah laku murid-murid Orang Asli dapat dilihat apabila amalan penggunaan media digital diguna pakai dalam PdP.

Menurut teori tingkah laku berencana, sikap diiktiraf sebagai penilaian yang positif atau negatif oleh seseorang individu terhadap tingkah laku yang tertentu dan dinyatakan dalam bentuk jangkaan hasil terhadap pelaksanaan tingkah laku tersebut. Sikap seorang murid Orang Asli terhadap pelaksanaan sesuatu perubahan dalam pembelajaran akan meningkatkan motivasi dan minatnya untuk belajar. Jangkaan manfaat dari perubahan iaitu penilaian positif individu terhadap tingkah laku berkenaan perubahan digunakan untuk mengukur sikap. Ini bermakna, murid Orang Asli yang mempunyai jangkaan manfaat dari perubahan yang tinggi akan menyokong sebarang perubahan yang dilakukan guru dalam bilik darjah.

\section{Kerangka Konseptual}

Berdasarkan teori tingkah laku berencana, terdapat tiga faktor utama yang mempengaruhi tingkah laku murid-murid Orang Asli menyokong perubahan dalam pembelajaran iaitu amalan penggunaan media digital, alat media digital dan tahap penguasaan media digital. Cadangan kerangka konseptual kajian adalah seperti berikut: 
Rajah 1: Kerangka konseptual pengetahuan dan tahap amalan guru dalam penggunaan media digital

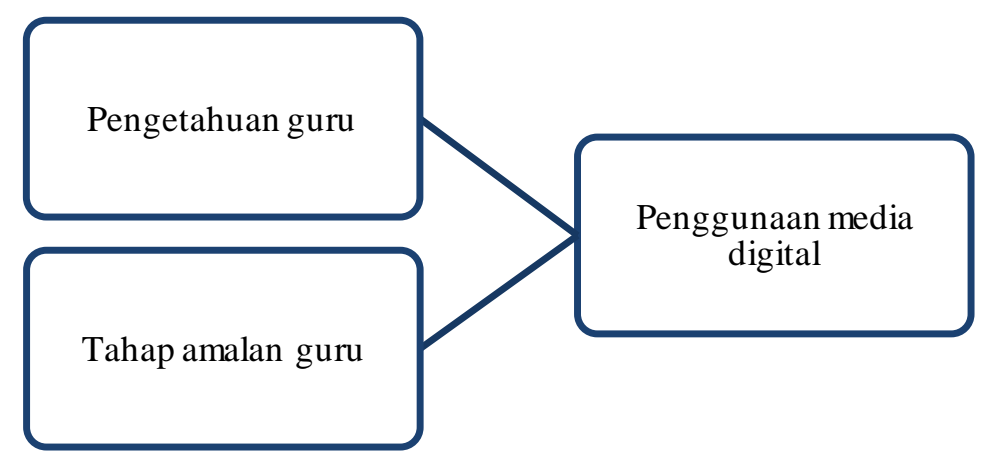

\section{Metod Kajian}

Metodologi kajian merangkumi reka bentuk kajian, populasi dan sempel kajian, instrumen kajian, kajian rintis, kesahan instrumen, kebolehpercayaan item, prosedur pengumpulan data, analisis data dan rumusan. Metodologi kajian berfungsi menentukan arah tuju sesuatu kajian melalui tatacara perlaksanaan yang dilakukan. Setiap maklumat kajian yang diterima perlu dijalankan dengan kaedah yang tertentu bagi memastikan maklumat yang akan dikeluarkan tepu dan keputusan yang akan diperolehi tepat (Majid, 2000). Dalam kajian ini, data akan dianalisis menggunakan perisian SPSS 24.0 melibatkan pengumpulan data menggunakan soal selidik.

\section{Populasi dan Sampel}

Populasi kajian ini melibatkan guru di dua buah sekolah iaitu Sekolah Kebangsaan Sungai Pusu Gombak dan Sekolah Kebangsaan Bukit Lanjan Damansara Perdana. Seramai 93 guru yang mengajar di Sekolah Kebangsaan Sungai Pusu Gombak dan 22 dari Sekolah Kebangsaan Bukit Lanjan Damansara Perdana.

Bagi tujuan penentuan jumlah dan saiz sampel kajian, pandangan pakar Krejcie \& Morgan, (1970) dan Cohen et al., (2001) dirujuk. Formula yang digunakan oleh mereka iaitu berpandukan kepada saiz populasi (Krejcie \& Morgan, 1970) atau aras kesignifikan pada $\mathrm{p}<.05$ iaitu sehingga 95 peratus pada tahap kebolehpercayaan data tersebut (Cohen et al., 2001). Berdasarkan jumlah populasi tersebut, keduadua sarjana ini mencadangkan jumlah sampel sewajarnya diambil di sekitar 79 orang ke atas. Memandangkan pengkaji berpendapat bagi mengelakkan ralat dalam persempelan (meningkatkan kepercayaan) pengkaji telah mengambil 110 orang sebagai sampel kajian.

\section{Instrumen Kajian}

Instrumen kajian yang akan digunakan dibangunkan sendiri oleh pengkaji dalam kajian ini merupakan satu set soal selidik yang mengandungi tiga bahagian. Bahagian A memperincikan mengenai demografi responden yang merangkumi jantina, umur, tahap pendidikan, pemilikan komputer peribadi dan kemudahan komputer di sekolah. Maklumat atau data berkaitan demografi belia ini adalah berbentuk data norminal yang mengandungi dua atau lebih kategori. Data dipersembahkan dalam bentuk kekerapan dan peratusan. Bahagian B memperincikan tahap penilaian guru mengenai media digital. Soal selidik di bahagian ini dibina sendiri oleh pengkaji merangkumi 10 item soalan dalam bentuk tertutup. Kesemua item-item tersebut diukur berdasarkan jawapan iaitu 1 (Ya) dan 2 (Tidak). Permakatan item ini diukur secara nilai kekerapan tertinggi dalam bentuk peratusan. Bahagian $\mathrm{C}$ memperincikan tahap amalan penggunaan media digital mengenai media digital. Soal selidik di bahagian ini dibina sendiri oleh pengkaji merangkumi 10 item soalan dalam bentuk tertutup. Kesemua item-item tersebut diukur berdasarkan skala Likert 5 markat iaitu dari (1) 
sangat tidak setuju, (2) tidak setuju, (3) tidak pasti, (4) setuju dan (5) sangat setuju. Permakatan item ini diukur secara nilai min iaitu 1-2.5 rendah, 2.6-3.5 sederhana dan 3.6-5 adalah tinggi.

Jadual 1: Interpertasi data kajian tahap penilaian guru mengenai media digital

\begin{tabular}{lcccc}
\hline \multicolumn{5}{c}{ Nilai peratusan (\%) } \\
\hline \multirow{2}{*}{ Interpretasi } & $0-50$ & $51-70$ & $71-90$ & $91-100$ \\
\cline { 2 - 5 } & Sangat rendah & Rendah & Sederhana & Tinggi \\
\hline
\end{tabular}

Jadual 2: Interpertasi dapatan kajian tahap amalan penggunaan media digital mengenai media digital

\begin{tabular}{ccc}
\hline $1-2.5$ & $2.6-3.5$ & $3.6-5$ \\
\hline Rendah & Sederhana & Tinggi \\
\hline
\end{tabular}

\section{Kajian Rintis}

Kajian rintis telah dijalankan sebelum kajian sebenar dilakukan. Tujuan utama kajian rintis ini dijalankan adalah untuk menguji kebolehpercayaan instrumen yang dibina. Justeru itu, untuk memastikan kesahan dan kebolehpercayaan instrumen, kajian rintis perlu dijalankan bagi memperoleh gambaran awal secara menyeluruh tentang mutu soal selidik yang disediakan dan menguji keberkesanan instrumen serta reka bentuk kajian.

Sebelum kajian yang sebenar dijalankan, satu kajian rintis telah dijalankan pada 4 Mei 2020 ke atas lima orang guru di setiap buah sekolah yang dipilih berjumlah 10 orang (Johanson, 2009).Lim(2007) menjelaskan, kajian rintis ini akan memperoleh maklumat awal tentang masalah instrumen dan anggaran tempoh menjawab yang diperlukan oleh responden. Data dari kajian rintis diproses menerusi perisian komputer SPSS versi 24.0 bagi menguji kebolehpercayaan.

\section{Kesahan Instrumen Kajian}

Secara umumnya pengkaji mendapati bahawa instrumen ini boleh diterima kerana hasil pra-uji menunjukkan semua nilai Cronbach's Alpha antara 0.821 hingga 0.860. Dapatan ini menunjukkan alat ukuran ini mempunyai alat psikometrik yang boleh dipercayai dan boleh digunakan dalam kajian sebenar (Pallant, 2010; Kline, 2011).

\section{Analisis Data}

Kajian ini akan di analisis melalui perisian SPSS versi 24.0 secara statistik deskriptif sahaja iaitu penggunaan peratusan sahaja. Statistik deskriptif bertujuan memperincikan demografi responden, manakala peratusan pula dilaksanakan bagi mendapatkan maklumat tentang pengetahuan media digital guru. Bagi min pula digunakan untuk melihat tahap amalan guru mengenai media digital, manakala penilaian secara purata pula digunakan melalui peratusan dan min tertinggi bagi menjawab objektif ketiga.

\section{Hasil Kajian}

Hasil dapatan kajian dilakukan secara terperinci dengan menggunakan kaedah kuantitatif bagi membolehkan pengkaji menguji objektif kajian yang telah dicadangkan. Bagi menjawab objektifobjektif dalam kajian, SPSS digunakan bagi menganalisis data statistik deskriptif. Kajian ini telah mengemukakan dapatan kajian mengenai penilaian pengetahuan guru dan tahap amalan penggunaan media digital di sekolah. Analisa yang diperoleh dalam kajian adalah merangkumi aspek: 


\section{Demografi responden kajian}

Seramai 110 orang responden yang terdiri daripada 59.1\% guru-guru perempuan, manakala $40.9 \%$ guru lelaki. Kebanyakan responden kajian berumur di antara 36 hingga 45 tahun iaitu $40.9 \%$ (45 orang). Hanya sekitar $4.5 \%$ sahaja (5 orang) yang berumur di antara 56 hingga 60 tahun. Tahap pendidikan responden juga menunjukkan secara majoriti $90.9 \%$ (100 orang) guru terlatih lepasan dari institut pengajian tinggi (kolej/universiti). Hanya 10 orang sahaja $(9.1 \%)$ guru tidak terlatih (bukan lepasan institusi pengajian tinggi). Secara umumnya kesemua responden kajian memiliki komputer peribadi. Walau bagaimanapun penyediaan komputer di sekolah kepada guru-guru di sekolah Orang Asli masih lagi di tahap tidak menyeluruh iaitu terdapat 4.5\% (5 orang) tidak disediakan kemudahan komputer.

\section{Penilaian pengetahuanguru terhadap media digital}

Daripada dapatan kajian menunjukkan tujuh item tentang penilaian pengetahuan guru terhadap media digital berada di tahap tinggi (nilai peratusan antara 90-100). Item-item tersebut adalah komputer ialah alat yang mudah dikendalikan, pendedahan awal berkaitan media digital sebelum mengajar, penggunaan perisian komputer selain Microsoft office, mengendalikan peralatan media digital di dalam bilik darjah, pencarian maklumat di dalam Internet, media digital menarik perhatian pelajar dan penggunaan e-mail. Walau bagaimanapun terdapat tiga item berada di peringkat sederhana (nilai peratusan 71-90) iaitu memperoleh maklumat media digital melalui kursus, membuat rujukan buku sekiranya menghadapi masalah media digital dan pembelian dalam talian.

\section{Amalan penggunaan media digital}

Dapatan kajian ini diukur melalui interpretasi dapatan kajian berdasarkan nilai min iaitu 1-2.5 adalah rendah, 2.6-3.5 adalah sederhana dan 3.6-5 adalah tinggi. Perincian dapatan kajian ini seperti diringkaskan dalam jadual 4.3 di bawah. Dapatan kajian menunjukkan kesemua responden (100\%) mempunyai tahap amalan penggunaan media digital yang tinggi dalam 10 item yang disenaraikan.

\section{Perbincangan Kajian}

Berdasarkan kajian ini, pengkaji mencadangkan kajian lanjutan dilakukan bagi memperbanyakkan literatur amalan penggunaan media digital dalam kalangan guru-guru dalam dimensi berbeza. Kajian ini mengukur penilaian pengetahuan guru terhadap medi digital dan tahap amalan penggunaan media digital guru-guru. Bagi mengukur penilaian pengetahuan guru-guru, kesemua item-item tersebut diukur berdasarkan jawapan iaitu 1 (Ya) dan 2 (Tidak) dan nilai kekerapan ditukar dalam bentuk peratusan. Manakala tahap amalan penggunaan media digital guru-guru, kesemua item tersebut diukur berdasarkan skala Likert 5 markat iaitu dari (1) sangat tidak setuju, (2) tidak setuju, (3) tidak pasti, (4) setuju dan (5) sangat setuju. Permakatan item ini diukur secara nilai min iaitu 1-2.5 rendah, 2.6-3.5 sederhana dan 3.65 adalah tinggi. Pengkaji merumuskan bahawa tujuh daripada 10 item yang melibatkan pengetahuan guru terhadap media digital berada pada tahap yang tinggi iaitu antara 90-100 peratus. Manakala nilai amalan penggunaan media digital dalam kalangan guru-guru Orang Asli berada di tahap yang tinggi dengan nilai min antara 3.909 hingga 4.318, manakala sisihan piawai pula menunjukkan nilai antara 0.447 hingga 0.671 .

\section{Kesimpulan}

Daripada dua dapatan objektif kajian ini, pengkaji merumuskan bahawa secara keseluruhannya amalan penggunaan media digital dalam kalangan guru-guru di sekolah Orang Asli adalah berada di tahap tinggi iaitu tujuh item melebihi nilai peratusan $90 \%$ (penilaian pengetahuan guru terhadap media digital) dan nilai min bagi item tahap amalan penggunaan media digital melebihi 3.6 ke atas. Berasaskan dapatan kajian, beberapa cadangan dibuat sebagai panduan penyelidikan pada masa akan datang. Pertama, kajian 
ini perlu diperluaskan kepada minat murid-murid Orang Asli terhadap media digital. Kedua, satu kajian perbandingan perlu dibuat kepada murid-murid Orang Asli di antara kawasan pendalaman, pinggir dan bandar. Ketiga, memperluaskan skop kajian kepada tahap literasi pengetahuan murid-murid terhadap media digital.

\section{Rujukan}

Abdul Razaq Ahmad \& Zalizan Mohd Jelas. (2009). Masyarakat Orang Asli: PerspektifPendidikan dan Sosiobudaya. Bangi: Penerbit UKM. 47-58.

Abdul Wahab Ismail Gani, Kamaliah Hj. Siarap \& Hasrina Mustafa. (2006). Penggunaan Komputer Dalam Pengajaran-Pembelajaran Dalam Kalangan Guru Sekolah Menengah: Satu Kajian Kes Di Pulau Pinang. Kajian Malaysia. Vol. XXIV. No. $1 \& 2$.

Abdullah, C. A. dan Ali, H. (2010). Penggunaan Teknologi Maklumat Dan Komunikasi (ICT) Dalam Kalangan Guru-Guru Sekolah Kebangsaan. Fakulti Pendidikan, Universiti Teknologi Malaysia.

Abu, B. dan Hoon, L. L. (2005). Tahap pengetahuan dan penggunaan computer dalam kalangan guruguru di tiga buah Sekolah Menengah Teknik di Kuala Lumpur. Fakulti Pendidikan, Universiti Teknologi Malaysia.

Ahmad, A., Abdullah, A. G., Ahmad, M. Z. \& Abd. Aziz, A. R. (2005). Kesan Efikasi Kendiri Guru Sejarah Terhadap Amalan Pengajaran Berbantukan Teknologi Maklumat dan Komunikasi (ICT). Jurnal Pendidikan, 7, 15-24.

Ahmad, S. F. dan Tamuri, A. H. (2010). Persepsi guru terhadap penggunaan bahan bantu mengajar berasaskan teknologi multimedia dalam pengajaran j-QAF. Journal of Islamic and Arabic Education, 2(2), 53-64.

Ang Kean Hua. (2016). Pengenalan Rangkakerja Metodologi dalam Kajian Penyelidikan: Satu Kajian Komprehensif. Malaysian Journal of Social Sciences and Humanities (MJ-SSH), 4(4).

Azlina Mohd Khir dan Ma'rof Redzuan. (2013). Atribusi kemiskinan dalam kalangan pelajar Orang Asli di Malaysia. Proceeding of the International Conference on Social Science Research, ICSSR 2013. 4-5 June 2013, Penang, Malaysia.

Christina Andin@ Nur Qistina Binti Abdullah\& Hazman Bin Ali. (2009). Penggunaan Teknologi Maklumat Dan Komunikasi (ICT) Dalam Kalangan Guru-Guru Sekolah Kebangsaan. T.tp

Doris Padmini Selvaratnam, Abdul Hamid Jaafar, Norlida Salleh, Redzuan Othman, \& Siti Hajar Idris. (2012). Transformasi Modal Insan Melalui Peningkatan Pendidikan: Kajian kes komuniti Orang Asli di Cameron Highlands, Pahang. Prosiding Perkem VII. Jilid 2, (pp.1215-1224).

Hasnuddin Bin Ab Rahman, Norfaizuryana Binti Zainal, \& Nor Azzarahton Binti Ab Karim. (2015). Keberkesanan Penggunaan ICT Di Dalam Pengajaran Dan Pembelajaran Pendidikan Islam Bagi Sekolah Kebangsaan Desa Pandan Kuala Lumpur. Proceeding International Conference on Information Technology \& Society (of IC-ITS 2015), 238- 252.

Hassan Mat Nor. (2009). Cabaran Pendidikan Masyarakat Orang Asli di Malaysia. Dalam Abdul Razaq Ahmad dan Zalizan Mohd Jelas (edt) Masyarakat Orang Asli: Perspektif Pendidikan dan Sosiobudaya. Bangi. Penerbit Universiti Kebangsaan Malaysia.

Hassan Mat Nor. (1998). Orang Asli dan Cabaran Masa Kini: Usaha dan Tindakan yang direncanakan

Johanson G.A.R \& Brooks G.P. (2009). Initial Scale Development: Sample Size for Pilot Studies. Educational and Psychological Measurement. SAGE Publications.

James \& Margaret. (2014). The honey ant readers: An innovative and bold approach to engaging rural indigenous students in print literacy through accessible, culturally and linguistically appropriate resources [online]. Australian and International Journal of Rural Education, 24 (1), 79-89

Jabatan Kemajuan Orang Asli. (2011b). Pelan Strategik Kemajuan Orang Asli (2011-2015). Kuala Lumpur: Jabatan Kemajuan Orang Asli Malaysia.

Jabatan Kemajuan Orang Asli. (2012). Laporan Tahunan JAKOA. Kuala Lumpur: Jabatan Kemajuan Orang Asli Malaysia.

Jabatan Kemajuan Orang Asli. (2018). Data Maklumat Asas Bahagian Pembangunan Modal Insan. Kuala Lumpur: Jabatan Kemajuan Orang Asli Malaysia.

Juli Edo. (2012). Pendidikan Orang Asli: Harapan dan Peluang. Dalam Ramle Abdullah, Mohamad Hafis Amat Simin, Azlina Abdullah dan Zurina Mansor (pnyt.) Pendidikan dan Orang Asli dalam Arus Perdana, hlm. 31-40. Kuala Terengganu: Universiti Sultan Zainal Abidin. 
Kementerian Pelajaran Malaysia. (2006). Pelan Induk Pembangunan Pendidikan (PIPP) 2006-2010. Kuala Lumpur: Bahagian Perancangan dan Penyelidikan Dasar Pendidikan, Kementerian Pelajaran Malaysia.

Kementerian Pendidikan Malaysia. (2013). Pelan Pembangunan Pendidikan Malaysia (PPPM) 20132025. Putrajaya: Kementerian Pendidikan Malaysia.

Kementerian Pendidikan Malaysia. 2013. Pelan pembangunan pendidikan Malaysia 2013- 2025. Putrajaya: Bahagian Pendidikan Guru.

Khadijah Abdul Razak, Tengku Norhayati Tengku Othman, Mohd. Isa Hamzah \& Hafizhah Zulkifli. (2014). Information and Communication Technology among Excellent Islamic Education Teachers in Selangor Malaysia. Journal International Education Studies. 7(13). 146-156.

Khairul Hisyam Kamarudin dan Ibrahim Ngah. (2008). Pembangunan Mapan Orang Asli. Skudai: Penerbit UTM.

Khairun Nisak Sombar@ Abdul Hamid, Maimun Aqsha Lubis, Mohd Aderi Che Noh, Hezlen Suzne Md Noor, Zawatil I'shqi Mustapa. (2016). Persepsi Pelajar Terhadap Penggunaan Youtube Dalam Subjek Pendidikan Islam. Prosiding wacana Pendidikan Islam Siri Ke 11 (WPI11),247-260

Ma'Rof Redzuan. (2010). Pembangunan dan Kemunduran Komuniti Peribumi: Kes kemiskinan dalam komuniti Orang Asli. Dalam Laily Paim dan Sharifah Azizah Haron (pnyt.) Kemiskinan di Malaysia: Isu Fundamental \& Paparan Realiti, hlm. 96-131. Serdang: Universiti Putra Malaysia.

Ma'Rof Redzuan dan Abdul Razak Abd Rahman. (2008). Integrasi Orang Asli dalam masyarakat arus perdana. Dalam Ma'Rof Redzuan dan Sarjit S.Gill (pnyt.) Orang Asli: Isu, Transformasi dan Cabaran, hlm. 252-283. Serdang: Universiti Putra Malaysia.

Mazdi Marzuki, Jabil Mapjabil \& Rosmiza Mohd Zainol. (2014). Mengupas Keciciran Pelajar Orang Asli Malaysia: Satu Tinjauan ke dalam Isu Aksesibiliti Sekolah. Malaysian Journal of Society and Space. 10 (2). 189-198

Maimun Aqsha Lubis, Wan Nurul Syuhada' Wan Hassan dan Mohd Isa Hamzah. (2017). Tahap Pengetahuan dan Kesediaan Guru-guru Pendidikan Islam Sekolah Menengah di Selangor Terhadap Penggunaan Multimedia dalam Pengajaran Pendidikan Islam. Asean Comparative Research Journal on Islam and Civilization (ACER-J) V 1(1), 1-13.

Marlina Sahaddin, Maimun Aqhsa Lubis, Mohd Aderi Che Noh \& Sitti Rafidah Sahaddin. (2016). Blended Learning Dalam Pengajaran Dan Pembelajaran Pendidikan Islam. Prosiding wacana Pendidikan Islam Siri Ke 11(WPI11). Hlm 557-568.

Mohd Fauzi Mohd Harun, NorAini Hj. Idris, Madeline Berma dan Faridah Shahadan. (2006). Kemiskinan di kalangan masyarakat Orang Asli. Jurnal Ekonomi Malaysia 40. 95- 101.

Mohd. Izham \& Noraini Attan. (2007). Tahap Kesediaan Guru Sains Dalam Penggunaan Teknologi Maklumat Berasaskan Komputer Dalam Proses Pengajran Dan Pembelajaran. Fakulti Pendidikan, UKM. Jurnal Teknologi, 46 (E), Jun 2007:45-60.

Mohd. Noorhadi Mohd Yusof \& Zurinah Tahir. (2017). Kepentingan Penggunaan Media Sosial Teknologi Maklumat dalam Pendidikan IPTA. Journal of Social Science and Humanities. 12 (3). $1-10$.

Nazariyah Sani. (2014). Pelaksanaan program literasi \& numerasi (LINUS): satu analisis. Tesis PhD. Kuala Lumpur: University Malaya.

Nicholas, C. (2006). The State of Orang Asli Education and Its Roots Problems. Retrieved Sept 19, 2009, from:

http://www.coac.org.my/codenavia/portals/coacv2/images/articles/OA\%20Education.pdf

Nicholas, C. (2000). The Orang Asli and The Contest for Resources: Indigenous Politic, Development and Identity in Peninsular Malaysia. Denmark: International Work Group for Indigenous Affairs

Nor Fariha Aniza Binti Md Isa, Nurul Nadia Binti Ahmad Sobri, SofanBin Hashnuddin. (2014). Analisis Trend Penyertaan Dan Keciciran Di Kalangan Pelajar Orang Asli. Fakulti Pendidikan. Universiti Kebangsaan Malaysia.

Nor Syazwani Mat Salleh, Rosseni Din, Intan Farhana Kamsin, Analisa Hamdan, Siti Zuraida Abdul Manaf, Aidah Abdul Karim, Mazalah Ahmad. (2015). Pembudayaan Literasi ICT Dalam Kalangan Pelajar Orang Asli Menerusi Persekitaran Pembelajaran Peribadi. Journal of Personalized Learning. 1(1), 45-56.

Noriati A. Rashid, Boon, Pong Ying, Sharifah Fakhriah Syed Ahmad \& Wan Kamaruddin Wan Hassan. (2012). Bab 5 dalam Teknologi dalam pengajaran dan pembelajaran. Edisi kemaskini. Shah Alam: Oxford Fajar Bakti. 
Nor āzilah Ngah dan Zarina. (1997). Perception of in-service teachers on the use of computers. Proceedings from the Malaysian Educational Technology Association $10^{\text {th }}$ Convention. Serdang: Universiti Putra Malaysia. May 21-23.

Ong Sze, Chong Zamri Mahamod \& Mohd Izham Mohd Hamzah. (2017) Meneroka Kaedah Pengajaran Guru Cemerlang Bahasa Melayu Negeri Sarawak: Satu Kajian Kes Kementerian Pendidikan Malaysia. Universiti Kebangsaan Malaysia. Issn: 2180-4842. Vol. 7, Bil. 1 (Mei 2017): 93-108.

Pallant, J. (2011). A Step by Step guide to data analysis using SPSS. 4th edition. Australia: Allen \& Unwin.

Padraig Wims \& Mark Lawler. (2007). Investing in ICTs in educational in developing countries: An evaluation of their impact in Kenya. International Journal of Education and Development using Information and Communication Technology (IJEDICT). Vol. 3, Issue 1, pp.5- 22.

Rogayah Bt Mohd Zain \& Mohd Aderi Che Noh. 2016. Kesan Globalisasi Ke Atas Pendidikan Islam Kini. Prosiding wacana Pendidikan Islam Siri Ke 11(WPI11). 35-42.

Rosmah Binti Abd. Ghani \& Mariani Md Nor (2014). Pelaksanaan Kurikulum Standard Prasekolah Kebangsaan oleh Guru Prasekolah Jabatan Pendidikan Prasekolah. IPG Kampus Sultan Mizan. Fakulti Pendidikan Universiti Malaya.

Sandra Rahman, Abu Bakar Nordin \& Norlidah Alias. (2013). Penggunaan ICT Merentas Kurikulum Standard Prasekolah Kebangsaan (KSPK): Tinjauan Di Prasekolah Kementerian Pelajaran Malaysia. Jurnal Kurikulum\& Pengajaran Asia Pasifik. Fakulti Pendidikan. Universiti Malaya.

Sharifah Nor Puteh \& Kamarul Azman. (2011). Tahap Kesediaan Penggunaan Ict Dalam Pengajaran Dan Kesannya Terhadap Hasil Kerja Dan Tingkah Laku Murid Prasekolah. Jurnal Pendidikan Malaysia. 36(1): 25-34.

Siti Hajar Binti Zakariah. (2013). Beban Tugas Guru Mempengaruhi Penggunaan Sumber Teknologi Pendidikan Di Empat Buah Sekolah Menengah Teknik Dan Vokasional di Johor. Fakulti Pendidikan Teknikal dan Vokasional Universiti Tun Hussein Onn Malaysia.

Syuhada Md Samsudin \& Mohd Aderi Che Noh. (2016). Pembudayaan Penggunaan Teknologi Dalam Pengajaran Dan Pembelajaran Pendidikan Islam. Prosiding wacana Pendidikan Islam Siri Ke 11(WPI11). 191-201.

Vespanathan Supramaniyam. (2015). Penggunaan Teknologi Maklumat dan Komunikasi (TMK) dalam kalangan guru-guru Mata Pelajaran Kemahiran Hidup di Sekolah Rendah Luar Bandar Negeri Johor. Tesis Sarjana. Batu Pahat. Universiti Tun Hussin Onn Malaysia.

Volman, M., \& Van Eck, E. (2001). Gender Equity and Information Technology in Education: The 2nd Decade. Review of Educational Research, 71(4), 613-634. Retrieved March 10, 2010, from Science Direct database.

Volman, M., Van, Eck E., Heemskerk, I., \& Kuiper, E. (2005). New Technologies, New Differences. Gender And Ethnic Differences In Pupils' Use Of ICT In Primary And Secondary Education. Computers \& Education, 45 (2005), 35-55. Retrieved March 6, 2010, from Science Direct database.

Zamri Mahamod, Norasmah Othman \& Mohammed Sani Ibrahim. (2008). Profesionalisme guru novis: Model latihan. Bangi: Penerbitan Fakulti Pendidikan, Universiti Kebangsaan Malaysia.

Zamri Mahamod. 2014. P\&P dalam pendidikan Bahasa Melayu. Cetakan Ketiga. Tanjung Malim: Penerbit Universiti Pendidikan Sultan Idris.

Zainal Abidin Ali. (2008). Peranan Jabatan Hal Ehwal Orang Asli (JHEOA) dalam pembangunan masyarakat Orang Asli. Dalam Maarif Redzuan \& Sarjit S. Gill (editor) (2008) Orang Asli: Isu, Transformasi dan Cabaran. Selangor: Penerbit Universiti Putra Malaysia.

Zainal Abidin Hj. Ali. (2012). Penilaian Terhadap Pelan Tindakan Pembangunan Pendidikan Orang Asli 2000-2010. Dalam Ramle Abdullah, Mohamad Hafis Amat Simin, Azlina Abdullah dan Zurina Mansor (pnyt.) Pendidikan dan Orang Asli dalam Arus Perdana, hlm. 43-58. Kuala Terengganu: Universiti Sultan Zainal Abidin.

Zainal Abidin Ali. (2019). Pendidikan Orang Asli: Ke Arah Lonjakan Kecemerlangan. Journal of Educational Research and Indigeneous Studies. 2(1) 